\title{
Ethics of Situated-ness, Sustainability and Ecology
}

\author{
Jin BAEK \\ Department of Architecture and Architectural Engineering, Seoul National University, Seoul, Korea
}

\begin{abstract}
This article illuminates the relationship between the human being and the surrounding things by referring to the philosophy of Martin Heidegger and Maurice Merleau-Ponty. Criticizing our habitual approaches to apprehending 'what a thing is', the two thinkers elucidate how 'what a thing is' can be understood only in conjunction with situations in the everyday and how humanity is joined with the qualities of the thing. In addition to the situated-ness of a thing, this article demonstrates the situated-ness of the human being, too, by referring to the notion of the horizon in the tradition of phenomenology. The last part of the paper discusses the basic premises of sustainability in reference to the situated-ness of both things and human beings. Framing natural things such as light as the alternative sources of energy propagandized in sustainability seems progressive. However, this attitude maintains fundamentally the same instrumental attitude we had towards nature, an attitude that has caused the current ecological crisis. By pointing this out, this article seeks to shape a ground for a broad spectrum of sustainability that embraces non-instrumental dimensions such as the practical, the ethical and the spiritual. This article also points out the limits of some of the currently available versions of ecology such as Shallow Ecology and Deep Ecology. In so doing, it seeks to lay out the parameters that any future version of sustainability and ecology needs to address..
\end{abstract}

Keywords : Situated-ness, Thing, Horizon, Sustainability, Ecology

\section{INTRODUCTION}

This paper comprises three sections. In the first section, I will lay out a philosophical basis for situated-ness by discussing the philosophy of Martin Heidegger (1889-1976) and Maurice Merleau-Ponty (1908-1961). Heidegger elucidates how "the thingly nature of a thing" can be properly understood only when one sees it as situated in the context of the daily life. Merleau-Ponty also clarifies how the qualities of a thing are intertwined with the qualities of humanity. The philosophies of these two thinkers remind us of different horizons each of which lets a particular facet of a thing to emerge. In this process, they lead us to rediscover the horizon of the everyday human situations as the most concrete context in which a thing manifests its thingness paradoxically in anonymity. It is art that brings this anonymous performance of a thing to visibility. The second section discusses the situated nature of the human being. As a way of overcoming anthropocentrism,

Corresponding Author: Jin Baek, Professor

Department of Architecture and Architectural Engineering,

Seoul National University

Daehakdong, Gwanakgu, Seoul, 151-744, Korea

Tel :+82 28807079 e-mail: jub34@snu.ac.kr

This is an Open Access article distributed under the terms of the Creative Commons Attribution NonCommercial License (http://creativecommons. org/licenses/bync/3.0/) which permits unrestricted noncommercial use, distribution, and reproduction in any medium, provided the original work is properly cited. there have been many notions in the tradition of phenomenology and hermeneutics that expound the pre-presence of the world in which one is found and situated: to cite some examples, Befindlichkeit, Stimmung and horizon. Among these, I will put my focus on the last theme. Here the aim is not to discuss and exhaust all the philosophical details of the idea of horizon, but to illuminate it in such a way that it has relevance to architecture and environmental ethics. Lastly, this paper will reflect upon what lessons the status of situated-ness of both things and human beings give rise to the discourse of sustainability. In so doing, this article criticizes the instrumental dimension latent within sustainability, and seeks to shape a ground for the restoration of a broad spectrum of sustainability that takes into consideration the plurality of the human living-plurality not in the sense of individualistic and isolated interests of human beings, but in the sense of diverse facets of humanity such as the practical, the ethical and the spiritual. I will also trace the development of different versions of ecology briefly in order to claim a necessity to formulate a new version of ecology based upon the situated-ness of things and the human being.

\section{SITUATED-NESS OF THINGS}

Martin Heidegger's and Maurice Merleau-Ponty's philosophies of the thing illuminate the status of things in human situations. First, they point out the errors in our habitual ways by which we understand the essence of a thing. One such way is the approach that sees a thing as a collection of properties: texture, color, smell, weight, hardness, resiliency and so forth. However, the limits of this approach are immediately clear. First, if we describe the properties 
of, for instance, the chalk, we will end up creating a formula with an almost infinite number of factors. In other words, as MerleauPonty points out, we may tire ourselves out before we even get close at all to what chalk is. Second, how the color is joined with the weight of the chalk, its shape, and its smell is not easy to explain in this formula. The chalk is an undividable totality. Borrowing Merleau-Ponty's phrase, this "unity" of the thing remains a mystery (Merleau-Ponty, 2008). Third, this formula is not able to explain how one property is reciprocal with another. One cannot sever tactility from the sound that occurs when one scratches the surface of a thing with fingers. Color also resonates with sound. A color makes a person sad, very much like a sound of a minor chord would make him or her equally sad. This resonance between color and sound is the reason why a blind person can image a color based upon the sound he or she hears. Merleau-Ponty (2008) writes of this correspondence between different properties with these words:

The unity of the object does not lie behind its qualities, but is reaffirmed by each one of them: each of its qualities is the whole. Cezanne said that you should be able to paint the smell of trees (p. 48).

Each seemingly fragmentary property entails some indication of the whole. In the case of painting, its aim was thus to capture the mysterious totality of a thing, not merely its color, shape or texture.

Another habitual way in our conception of 'what a thing is' is what is called the Democritian approach. A thing is continuously dissected until one reaches a point where no further dissection is possible. This is the level where we see molecules, atoms, neutrons, electrons and so forth. Heidegger is critical of this approach. This approach on the horizon of science reveals only an aspect of a thing in a highly abstracted and fabricated relationship between man and the thing. When one cuts a piece of chalk into two halves to see its inner essence, he or she is merely led to two pieces of chalk. Further invasion into the depth of the chalk will merely lead to a greater number of pieces of chalk: four, eight, sixteen, thirty-two and so forth. While we may get the facet of the chalk composed of molecules, atoms, electrons, and so forth, according to Heidegger, the chalk-ness of the chalk has vanished. In fact, the pile of dust left after a series of dissections leads us no closer to the essence of the chalk than the unbroken original status of the chalk.

While there are other habitual ways of conceiving the essence of a thing, what is important is not to list all, but to figure out why Heidegger and Merleau-Ponty criticize these conventional ways. That is because they would like to refresh our relationship with things and bring to our attention a horizon on which they manifest their thingness. This horizon is none other than the horizon of the everyday life. Let me quote a passage by Heidegger (1993) in which he explicates our intimate relationship with things in the context of daily situations:

If we consider moreover what we are searching for, the thingly character of the thing, then this thing-concept again leaves us at a loss. We never really first perceive a throng of sensations, e.g., tones and noises, in the appearance of things-as the thing-concept alleges; rather we hear the storm whistling in the chimney, we hear the three-motored planes, we hear the Mercedes in immediate distinction from the Volkswagen. Much closer to us than all sensations are the things themselves. We hear the door shut in the house and never hear acoustical sensations or even mere sounds. In order to hear a bare sound we have to listen away from things, divert our ear from them, i.e., listen abstractly. . . In [this abstraction] the thing vanishes. (“The Origin of the Work of Art," pp. 151-152)

In this writing, Heidegger clarifies that our perception of a thing is not destined towards fragmentary conditions of a thing, but its totality as situated in the context of the human life. We do not see white color, but we see a chalk sitting on the tray of a blackboard in a lecture room. A thing and how it is situated go together. This also means that the identity of a thing is not in itself, but in its relationship with other things in formulating and supporting a situation. Because of this network of relationships in which each thing assumes a different role in formulating an ideal human situation, Heidegger claims that the nature of a thing is the "gathering" of other things around itself (Heidegger, "Building, Dwelling, Thinking," 1993, p 355). A chalk refers to a blackboard; a blackboard refers to a wall on which it is hung; a wall refers to a floor and a ceiling; the floor refers to the terra firma on which it sits and the ceiling refers to the sky as the ultimate roof, and so forth.

An example by which we may understand Heidegger's and Merleau-Ponty's notion of the thing is a painting entitled, The Book (Figure 1) by Juan Gris (1887-1927), a leading artist of Cubism. First of all, like other painters at the turn of the century, Gris was interested in depicting things of the daily life, not the themes of the traditional painting such as religious stories, figures, and landscapes. Looking at the painting, as the title implies, we find a book in the central part of the canvas. Yet, this painting is

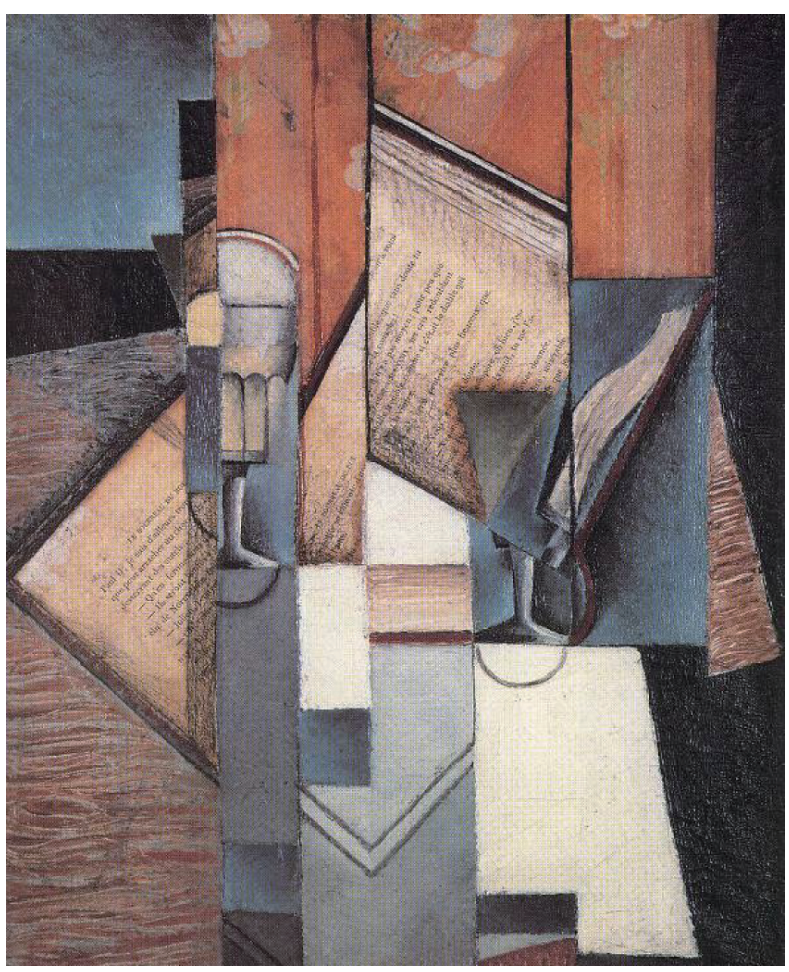

Figure 1. Juan Gris, The Book, 1913 
unique in that the profile of the book is not separated from the surrounding things. The profile of the book seems even incomplete. It is penetrated here and there by other things. It also overlaps the profiles of the surrounding things. Gris paints a book not as an independent object, but as a thing laid out in the context of the situation of reading a book. A scholar, particularly in the context of Europe, would have a glass of wine and a pipe on the table when he or she reads a book. Then there are the more or less architectural elements such as the floor, the wall and the window with a halfopen curtain. And then finally there are the entities that are not designed or created, but are given: the earth, the sky and the horizon.

What is important here is to understand the role of art in letting the essence of a thing come to visibility. Heidegger points out the paradox that when a thing is manifesting its essence by performing its role properly in supporting a human situation, it does not grab human attention. A thing hides itself at the very moment when it is working appropriately. When a hammer operates properly, the carpenter never pays attention to it. In other words, he or she does not thematize the hammer as such, as an object now dislocated from the network of things that support a situation. It is only when the hammer is not operating properly that we give our full attention to it and analyze its parts and properties to figure out the source of the problem. This phenomenon, or the paradoxical anonymity of a thing, illuminates the intimacy that exists between man and the thing. The thing is anonymously available. It is the work of art that brings the thing to visibility, like the painting by Gris that lets a book, along with other things, emerge as thematized, while not transforming it into an object dislodged from a situation.

\section{SITUATED-NESS OF THE HUMAN BEING}

If a thing is situated, is the human being situated, too? Or, is the human being a privileged entity separated from a given situation and in control of it? What the tradition called phenomenology and hermeneutics led by Edmund Husserl (1859-1938), Heidegger, Merleau-Ponty, Paul Ricoeur (1913-2005), Hans-Georg Gadamer (1900-2002), and so forth continuously confirms is that man is situated. Gadamer's discussion of the significance of 'preunderstanding' in apprehending a phenomenon or a text is a good example. Gadamer saves the significance of 'pre-understanding' from the prejudice of the Enlightenment that prejudice itself is always detrimental (Gadamer, 1999). Gadamer's immediate reference for this hermeneutical structure is Heidegger's notion of Dasein. Dasein, or the being-in-the-world, is always found in a mood (Stimmung), a phenomenon which Heidegger named with a neologism Befindlichkeit (Heidegger, 1962). MerleauPonty's idea of perspectivism also ascertains the situated-ness of the human being in his or her relationship with the surrounding world (Merleau-Ponty, 1963). According to this idea, one can see only three faces of a cube at each time. While the cube itself is a finite thing, in its appearance it is infinite. In this fashion, one is always in an angular relationship to a thing in which a facet of a thing, or partiality of a thing, emerges. A partial image of a thing does not point to the impossibility of communicating with other partial images, but rather points to a necessity to join one with another in order to reach a fuller understanding of the whole.

In order to illustrate the situated-ness of the human being, however, I'd like to focus on the horizon, an idea that appeared in Husserl's Ideen in 1913 and was developed further by Heidegger. The horizon is a line that emerges when, for instance, the earth encounters the sky. The first point that characterizes our relationship with the horizon is that we are surrounded by the horizon. We do not stay above the horizon. Simultaneously, nobody can be beyond the horizon. Even if we run to escape from the horizon, a new horizon always appears and captures us inside. In this sense, to put it negatively, we are trapped and even imprisoned. To put positively, however, we are situated. The horizon also bounds an inside. It demarcates a region where things appear. It formulates an openness in which things come to intelligibility. The sense of distance in the lived experience of the world is articulated by the presence of the horizon, too: foreground, middle ground, and far ground. Things also appear either above the horizon, or below the horizon, or on the horizon. If the horizon disappears, the perceptual structure of the world composed of the foreground, middle ground and far ground, and composed of above and below, comes to rupture, too. We lose the openness where things come to intelligibility. We lose the frame that would allow things to emerge. The dialectic between what is known in the openness and what is unknown beyond the horizon disappears, too. We discover ourselves hovering in cosmos, which is direction-less, orientation-less, scale-less, and extending infinitely. For all these reasons, the horizon has become a favorite metaphor for a fundamental human condition that we have been thrown into a specific frame of time and location, a characteristic in Heidegger's definition of Da-sein.

In clarifying the significance of the horizon further, it would be useful to differentiate two horizons. I'd like to call the horizon I have been discussing as the emblem of our situated-ness the phenomenal horizon. The other horizon is what I would like to call the geometrical horizon. The geometrical horizon is the basis for perspective. Perspective is a method of representation, whose laws, as has been studied by many, were first articulated by Filipo Brunelleschi (1377-1466) in the early $15^{\text {th }}$ century and geometrically demonstrated by Leon Battista Alberti (1404-1472) in his treatise entitled De Pictura (1435, English translation: On Painting), which he dedicated to Brunelleschi. The starting point of perspective is based upon the visual phenomenon that objects appear to the eye as diminishing as they recede from the viewer. Parallel lines and planes appear to converge to an infinitely distant vanishing point.

There is a very intriguing aspect about the vanishing point. Even though it is called a vanishing point, its location cannot be fixed. At a moment one thinks that one has arrived at the vanishing point, he or she realizes that the point has just outdistanced him or her. And, it is not just a stone's throw away. There is a gap of almost eternity, because the vanishing point continuously and incessantly moves farther away from the viewer. This all means that even though it is called a point, the vanishing point is not a normal point. A normal point defines a position, but the vanishing point defines not a point, but an axis along which one can progress infinitely. Space in perspective is thus pure extension of infinity. Accordingly, MerleauPonty characterizes the gaze of the perspective as the "gaze fixed at infinity" (Merleau-Ponty, 2008, p. 53). He also calls the perceiver who is seeing the vanishing point at infinity "an absolute observer" (Merleau-Ponty, 2008, p. 54), a theoretical observer remote from the real subject of perception. 
At this moment we need to differentiate Merleau-Ponty's perspectivism from his criticism of perspective. What he calls perspectivism refers to our lived experience of the world in which things appear in an angular relationship in the openness set by the phenomenal horizon. In contrast, perspective as a technique is only an approximation of our real experience of the world in the process of which it sets its own geometrically-conceived horizon. In this sense, perspective as a technique is fictitious. The one who gazes at infinity is not the one situated in the world. While facing the vanishing point, he or she sees, and gives equal amount of attention, to every corner of the world. It examines the world, to a degree, like a camera that can scan the world with an indifferent gaze. But, this is not the way the human perception unfolds. According to human physiology, there is no single moment in which one can give attention to two or more different things. (A simple experiment in which one tries to see two neighboring fingers at the same time verifies this point). One sees a thing at a moment, and at this moment, the remaining things recede to the silent background. Then, he or she moves the focus to another thing. At that moment, what grabbed his or her attention previously now recedes to the background so that the focus may be given to the new thing of attention. In other words, the lived visual experience operates upon the dialectic between what appears and what recedes. As MerleauPonty states, there is always the background of silence that lets a thing to emerge. It is a zone of latent articulation. In perspective everything appears; in perspectivism, or the real perception of the world, there is a dialectic between emerging and receding.

\section{SITUATED-NESS, SUSTAINABILITY AND ECOLOGY}

The situated-ness of things and human beings in the world has significant lesson for the contemporary interest in sustainaiblity. First, the situated-ness of things makes clear the problem of modern technology. The problem was none other than dislocating a thing from its situated-ness so that the thing is turned into an object of manipulation. In other words, at the basis of the operational logic of technology is the transformation of a thing situated in a context into an object dislocated from the context. Once a thing is taken out of a situation, it can be played by at the whims of the human beings. Once separated from the situation in which there are an eraser, a board, then a wall, a floor and a ceiling with lights illuminating the board, a chalk can be cut, hit, pressed, thrown, kicked, broken and so forth under the cause of apprehending its essence. As Heidegger criticizes, at the basis of the conception of the earth as a "standingreserve" (Heidegger, "The Question Concerning Technology," 1993, pp. 320-322, 325) of raw materials is this dislocation of things from their situational contexts.

Sustainability assumes a positive role in the contemporary situation of energy crisis. It points out the shortage of raw materials and of the sources of energy. The earth that was seen as containing abundant materials and resources has now been revealed as limited. Sustainability also points out that we all are held responsible for the current crisis, and it seeks to avoid making any further environmental deterioration. Sustainability pours efforts to discovering and utilizing new resources of energy, in particular renewable elements such as light, wind, rainwater and so forth.

However, a fundamental question we need to pose as to the current crisis is not so much about the energy crisis as about the relationship we have had with things. Without reflecting upon this issue of the relationship, figures, who are vocal about sustainability, often make crude assertions. One example is James Wines, a supposed leader in sustainability. For him, the basis of sustainability is "to advance the purely selfish motive of survival by a cooperation with nature" (Wines, 2000, p. 15). In order to overcome this kind of uncouth perspective of sustainability, we need to understand that the shortage of energy itself is not the gist of the problem. It is merely the result of our relationship with the surrounding things and our attitude towards the world. In this context, we need to reflect upon the hegemonic attitude we had in the process of transforming the world into a storehouse of resources, a storehouse that can be appropriated at the whims of the human being seeking productions, profits and materialistic affluence.

In endeavoring to utilize natural elements such as light, wind and rainwater, which would cause no pollution, sustainability seems progressive. However, there is an intriguing dimension in this. One has to ask whether our attitude towards the world has fundamentally changed in this case. Light, wind and rainwater are unique things. They don't have fixed profiles. They are in a constant movement in fluidity and unboundedness. Accordingly, their status was defined as ek-stasis ("existence" comes from this Latin word). Along with the fact that there was not much need to pay attention to the natural elements, because the earth was seen as an abundant storehouse, their exceptional ontological condition as $e k$ stasis made our framing and manipulating them difficult. With the advent of sustainability, however, this has changed. Now we frame them from the perspective of their capacity to produce energy with no side effects of pollution. Is this attitude still not the same as the attitude that conceived nature as the storehouse of materials and resources of energy? In his criticism of modern technology, Heidegger's point is that we need to forsake this manipulative or hegemonic attitude about the things in the world. In addition, he awakens us to the fact that the thingness of a thing cannot be manipulated, as it vanishes in the midst of our focus on properties, sensations, atoms and so forth.

There is another issue in reference to the treatment of natural elements. While focusing on sustainability, we often forget the fact that there is an indivisible investment of humanity, or 'who we are,' in natural elements. Merleau-Ponty (2008) wrote of this fact with these words:

Our relationship with things is not a distant one: each speaks to our body and to the way we live. They are clothed in human characteristics (whether docile, soft, hostile or resistant) and conversely they dwell within us as emblems of forms of life we either love or hate. Humanity is invested in the things of the world and these are invested in it. (p. 49)

Merleau-Ponty's example to illustrate this intertwined relationship between the qualities of natural elements and humanity is water. Water never comes as $\mathrm{H}_{2} \mathrm{O}$ or water as such that is separated from the context of the human life. Rather, it always comes with qualities that are inseparably connected with 'who we are.' To verify this point, Merleau-Ponty introduces a poem in which the poet writes of water as a perfect embodiment of a human ideal: humility. Why does water appear as the embodiment of humility for the poet? That 
is because water always finds the lowest point in a given topography. Water always gives itself out to a form, as if it had no ego. It is also sensitive to what slight change that may occur in a given setting. And lastly, it lies completely flat on the floor, like those monks of an order who are vowing complete humility before a divine being. When we look at water this way, its quality is inseparably connected with humanity, or 'who we are': we struggle to seek humility, modesty, sensitivity, and ego-lessness. Is there a better emblem of this noble desire of the human being than water? Water, its self-humiliating movement, sets the standard against which one's humility can be measured. Water is the index in reference to which man's modesty can be tested. From water, we see what we are aspiring.

With this reciprocity between the qualities of natural elements and humanity in mind, let me introduce a chart below. This chart presents different levels in which we are related to water. It also shows how our relationship with water at one level is more primary than our relationship with it at the level immediately below.

\section{A Reflecting Pool in a Crematorium 仓} 4. A Reflecting Pool

仓

3. A Pool

仓

2. Water

仓

1. $\mathrm{H}_{2} \mathrm{O}$

Starting from the bottom, before we see $\mathrm{H}_{2} \mathrm{O}$, we see water. Water is closer than $\mathrm{H}_{2} \mathrm{O}$. Before we see water, we see a pool. The pool is closer to us than a physical body of water. Furthermore, before we see a pool, we see a reflecting pool. Before we see a reflecting pool, we see a reflecting pool in a crematorium. Our perception of a part is always transcended by our intuitive understanding of the whole. As we move upward, our relationship with water becomes highly concrete. The behaviors of water, its stillness at a lowest given topography, coalesce with the heart of the human beings in a ceremony in a crematorium. At this level, natural things are intertwined with humanity. The water resonates with the solemn, peaceful and meditative nature of the ritual. In contrast, as we move downwards, water comes to be dislocated from a concrete human situation to be an element in itself. It is severed from concrete human situations. Level 5 is where poetic, artistic and architectural imaginations operate. In contrast, level 2 , as well as level 1 , is where technology and science operate. My assertion is that sustainability that separates natural things like water from concrete human situations and that frames them from the perspective of the production of energy locates itself at level 2, if not level 1.

Examined this way, the limits of our instrumental attitude towards nature are quite clear. It simplifies human situations in reference to energy performance and efficiency. It lacks a framework that can accommodate human activities that are not necessarily bound to the optimization of an energy pattern. Furthermore, cultural acts, such as a ritual, involve moments that are fundamentally unsustainable. Let's imagine a person in the hot summer of Mexico city. A person who walks on knees in a piazza towards a church at one side to make repentance involves, from the perspective of instrumental sustainability, an unwise waste of energy. In order to be able to exert such a level of energy, he or she has to have more food. This means that more land needs to be cultivated. This may involve the cutting of more trees. Therefore, a ritual appears fundamentally anti-sustainable at least to a certain degree. Does this mean that in the midst of energy crisis, we shall give up rituals? If we give up rituals, then what is left of what is called culture and even of humanity? These are the questions sustainability should tackle in order to overcome the narrowness of the spectrum in which it understands humanity.

A similar attitude of instrumentality is also observed in some versions of ecology. Environmental Ethics, in which ecology is a subject matter, was developed in the 1970s as a field of "Applied Ethics." This formation of environmental consciousness was the result of environmental pollution. Environmental pollution itself was in turn the result of the Euro-centric and American-led process of modernization with the motto of conquering nature, as well as primitive peoples and nations. Seen this way, Environmental Ethics is the very reflection of the crisis that was felt by the West, as well as by those countries that quickly followed the track of the West. While there are many versions of ecology that emerged in response to this situation, I'd like to comment on two, because they operate as reference points in the history of ecology for their diametric contrast regarding the relationship between man and nature. The first is what was later labeled by its opponents as Shallow Ecology (Kioka, 2007). The goal of this ecology was to conserve nature. Nature as the container of the resources that would enrich materialistically human living was slowly discovered as being limited in her stock. Accordingly, man has to slow down the phase of development, and manage and control nature in such a way that its stock is not depleted. On account of these reasons, for those who criticized this version of ecology, it was seen as still anthropocentric.

What appeared in response to this Shallow Ecology was what is called Deep Ecology. This version of ecology seems radical. It decentralizes man. Nature, or its organic totality, is the center. Every entity in nature has an inherent right to prosper, not to be controlled by man. Each entity in nature has its own inherent value not to be distorted by man based on his or her own interests. Man himself or herself is none other than an intelligent animal (Kioka, 2007). In claiming inherent right and value for an entity, "Deep Ecology" draws its justification from the philosophy of Heidegger. Heidegger's criticism of transforming a thing into an object of manipulation grounds Deep Ecology's assertion on the innate value of a thing. It also resonates Heidegger's claim that the facets of a thing we may get out of treating it as an object displaced from a situation do not lead us to the discovery of the thingness of the thing. As claimed, a thing cannot be manipulated. In the manipulation of a thing is an illusion that the facets we have squeezed out from it are the thingness of the thing. As a matter of fact, the thingness hides itself, while we may relish with its tertiary and even misleading facets. 
However, Deep Ecology does not seem to fully understand Heidegger's point. It is correct that a thing has its own thingly nature that cannot be perceived by a man whose major interest is to extract energy. It is also natural to assume that man does not understand the inherent value of a natural element such as rocks, trees, animals and so forth. However, Heidegger's point is that the truthful essence of a thing does not lie in the zone of the metaphysics of Ding an sich, but manifests itself in a human situation. In his later writing entitled, "Building, Dwelling, Thinking," Heidegger also clarifies that it is through, for instance, a bridge-a built thing-that the essence of the sky, the river, the banks, the fields, and mortals appear (Heidegger, "Building, Dwelling, Thinking," 1993). Put differently, through the intervention of a human creation, things and 'what they are' come to visibility. Without this constructive intervention, nothing would appear. Heidegger's position may seem anthropocentric, in that things appear in reference to human situations and in that human intervention is crucial. However, it is not anthropocentric in that the human beings themselves are, as discussed in the second section, situated. In other words, the prepresence of the world of which the phenomenal horizon is the emblem dislocates man from anthropocentrism. Man is not above the world. Nor is he or she at the center of the world. Rather, he or she is situated. In addition, man is from the beginning intertwined with the qualities of the things to the point that one cannot separate himself or herself from the things without disrupting profoundly what he or she is. In this regard, the flaws in Deep Ecology seem clear. This also means that we are facing a need to formulate another version of ecology that must be able to explain this duality: not being anthropocentric, yet being still about human situations.

\section{CONCLUSION}

Now, in a way, we seem to be standing at a historical moment in which we are probably applying the hegemonic attitude to the natural elements such as light, wind, rainwater, and so forth. In this process, few people seem to understand that actually our relationship with them is not simply positivistic, materialistic and instrumental. If there is a danger behind sustainability, it is none other than the fixation of our relationship with the surrounding things on their potential in producing energy. To be sure, this statement should not be taken as dismissing our instrumental relationship with natural elements. Rather, it means that we need to have a spectrum in which various levels of the significance of natural elements are understood and practiced.

I believe refreshing us with Heidegger's and Merleau-Ponty's points about our relationship with the surrounding things and our situated-ness in the world offers parameters with which we may move forward beyond Shallow Ecology and Deep Ecology. The new version of ecology must reflect upon the limit of the habitual dichotomous division between man and the surrounding environment, if humanity and the qualities of the things that surround us are indivisibly intertwined. Not being able to present an alternative at the moment, I acknowledge both the limit of this study and a necessity for a future study that delves into the intersection between ecology and phenomenology.

While there is yet no clear route to follow, however, it seems still possible to find a promising lead: the environmental ethics of Tetsuro Watsuji (1889-1960), a leading modern Japanese thinker. I find his notion of fudo, or climate, to be entailing a significant potential. Fudo is the milieu in which nature and man are intertwined with each other. In this milieu, a seemingly natural quality operates as the metaphor of humanity. In addition, Watsuji illustrates how fudo is the agency for the formation of collective cultural measures. In other words, it opens a theoretical space for the understanding of how fudo, or the inseparable concrete bond between man and nature, has implications for the relationship between man and man, or the ethics of the inter-personal (Watsuji, 1961; Watsuji, 1996) This point also seems to echo the etymological meaning of ecology: Ecos, which was the hearth in the Greek residence, was not merely about a man standing near the source of heat in the middle of coldness, but from the beginning about a group of people sharing a limited source in a balanced way.

\section{REFERENCES}

Alberti, Leon Battista. (1991), On Painting (De Pictura). trans. Cecil Grayson, London: Penguin Books.

Gadamer, Hans-George. (1999) Truth and Method. trans. Joel Weinsheimer and Donald G.. Marshall. New York: Continuum.

Heidegger, Martin. (1962) Being and Time. trans. Macquarrie and Robinson. New York: Harper and Row.

Heidegger, Martin. (1993) “The Origin of the Work of Art." in Basic Writings, ed. David Farrell Krell, New York: HarperCollins Publishers, pp. 139-212.

Heidegger, Martin. (1993) “The Question Concerning Technology." in Basic Writings, ed. David Farrell Krell, New York: HarperCollins Publishers, pp. 311-341.

Heidegger, Martin. (1993) “Building, Dwelling, Thinking, in Basic Writings. ed. David Farrell Krell. New York: Harper and Row, pp. 343-363.

Kioka, Nobuo. (2007) "The Problem of Environment from the Viewpoint of Mesology (Fudogaku kara mita kankyoumondai)." Journal of Volunteer Studies . 8: 19-34.

Merleau-Ponty, Maurice. (2008). The World of Perception. New York and London: Routledge.

Merleau-Ponty, Maurice. (1995) Phenomenology of Perception. New York and London: Routledge.

Merleau-Ponty, Maurice. (1963) The Structure of Behavior trans. Alden Fisher. Boston: Beacon Press.

Watsuji, Tetsuro. (1961) Fudo (A Climate: A Philosophical Study). trans. Geoffrey Bownas, Tokyo: Ministry of Education Printing Bureau.

Watsuji, Tetsuro. (1996) Watsuji Tetsuros Rinrigaku, Ethics in Japan. trans. Yamamoto Seisaku and Robert E. Carter, Albany: State University of New York Press.

Wines, James. (2000) "The Art of Architecture in the Age of Ecology." in Sustainable Architecture White Papers. Laval, Quebec: Quebec Printing. pp. 12-18.

(Date of Submission : 2010.11.3) 